\title{
Genetic and epigenetic concept of SARS-CoV-2 targets in different renal cancer subtypes
}

\section{Farklı Böbrek Kanseri Alt Tiplerinde SARS-CoV-2 Hedeflerinin Genetik ve Epigenetik Konsepti}

https://doi.org/10.1515/tib-2020-0233

Received May 13, 2020; accepted November 6, 2020; published online January 5, 2021

\begin{abstract}
Objectives: Recent advances in defining the genetic landscape of has shown the host cell- SARS-CoV-2 interaction via ACE2 protein and the presence of at least three additional virus invasion genes including TMPRSS2, FURIN, CD147/BSG. In current study, we investigated the mutation and $\mathrm{m}$-RNA expression patterns of target genes by evaluating the associations between genetic and epigenetic mechanisms in the target genes and susceptibility of SARS-CoV2 infection of renal cancer subtypes.

Methods: We investigated the mutation and m-RNA expression patterns of our target genes. The promoter methylation profiles of target genes were tested in the UALCAN database.

Results: The total rate of carrying genetic anomaly in the target genes including was $1.6 \%$ and seven mutations, one of which had a pathogenic feature, were detected. The expression analysis results in renal cancer groups showed that while the KIRC and KIRP patients had a lower level of TMPRSS2 than the healthy control, their ACE2 level was high. KICH patients had a higher level of
\end{abstract}

*Corresponding author: Rahsan Ilikci Sagkan, Department of Medical Biology, School of Medicine, Usak University, Usak, Turkey, Phone: +90 276 3212121, ext 4304 Fax: +90 276 3212121, E-mail: rahsan.ilikci@usak.edu.tr. https://orcid.org/0000-00033844-6158

Dilara Fatma Akin-Bali, Department of Medical Biology, Faculty of Medicine, Nigde Omer Halisdemir University, Nigde, Turkey. https:// orcid.org/0000-0002-0903-0017
CD147/BSG expression than the healthy group. The promoter methylation levels of ACE2 in KIRC and KIRP were reduced.

Conclusions: We concluded that renal cancer patients may be more sensitive to SARS-CoV-2 infection, which may worsen the prognosis.

Keywords: ACE2; CD147/BSG; COVID-19; FURIN; methylation; renal cancer; Severe acute respiratory syndrome coronavirus 2; TMPRSS2.

Öz

Amaç: SARS-CoV-2 virüs ve konakçı hücre interaksiyonunun tanımlamasındaki son genetik gelişmeler, ACE2 proteinini ve TMPRSS2, FURIN, CD147/BSG'yi içeren en az 3 ek virüs istila geninin varlığını göstermiştir. Bu çalışmada, hedef genlerde genetik ve epigenetik mekanizma ile farklı böbrek kanseri alt tiplerinin SARS-CoV-2 enfeksiyonunun duyarlılığı arasındaki ilişki değerlendirilecektir.

Gereç ve Yöntemler: Hedef genlerimizin mutasyon profilini ve m-RNA ekspresyon paternini araştırdık. Ek olarak, hedef genlerin promotör metilasyon profilleri UALCAN veritabanında test edilmiştir.

Bulgular: ACE2, TMPRSS2, CD147/BSG ve FURIN dahil olmak üzere hedef genlerin toplam genetik anomali taşıma oranı \% 1,6 bulundu ve tespit edilen 7 mutasyondan 1 tanesi patojenik özelliğe sahipti. Gen ekspresyon analiz sonuçlarına göre farklı böbrek kanseri gruplarında; TMPRSS2 düzeyi KIRC ve KIRP hasta grubunda sağlıklı kontrole göre istatistiksel olarak anlamlı olarak düşerken, ACE2 düzeyi KIRC ve KIRP'de yüksek bulundu. CD147/BSG ekspresyonu, KICH hastalarındaki sağlıklı daha yüksektir. KIRC ve KIRP'deki ACE2 hızlandırıcı metilasyon seviyelerinin azaldığı görüldü. 
Sonuç: Böbrek kanseri hastalarının prognozunu kötüleştirebilecek SARS-CoV-2 enfeksiyonuna daha duyarlı olabileceği sonucuna varılmıştır.

Anahtar Sözcükler: ACE2; böbrek kanseri; CD147/BSG; COVID-19; FURIN; metilasyon; Şiddetli akut solunum sendromu koronavirüs 2; TMPRSS2.

\section{Introduction}

COVID-19 is a major cause of death for the humankind worldwide because of its pandemic characteristics. Severe acute respiratory syndrome coronavirus-2 (SARS-CoV-2 disease: COVID-19) is one of the most common infections that affect humans nowadays [1-3]. Under normal circumstances, the kidney is sterile and infection develops only when a microorganism's virulence overcomes normal host defense mechanisms, however; cancer may also increase the susceptibility to infections [4]. Several researchers around the world reported the SARS-CoV-2 infection to be the most common organism that infects cancer patients [5]. Biochemical interaction and structure studies showed that the SARS-CoV-2 spike protein had a strong binding affinity to human Angiotensin Converting Enzyme-2 (ACE2). Further analysis suggested that SARS-CoV-2 also recognized human Basigin (CD147/BSG) protein as well as the human ACE2 target (these alternative binding options are required for host cell entry and subsequent viral replication [6-8]. This process of entry is critical. The viral genome of SARS-CoV-2 encodes various proteins. Viral RNA is translated into a long polypeptide which must be digested by the protease enzymes for functional proteins $[9,10]$.

Hoffman et al. reported that transmembrane protease serine 2 (TMPRSS2), which is priming the spike protein essential for virus invasion, hosted cells. The other serine protease system is paired basic amino acid cleaving enzyme (FURIN/PCSK3) [10]. Renal cancer is heterogeneous cancer which is divided into three renal cancer subtypes as Kidney Chromophore (KICH), Kidney Renal Clear Cell Carcinoma (KIRC), Kidney renal Papillary Cell Carcinoma (KIRP) [11]. The kidney is one of the organs targeted by this virus. COVID-19 is a predicted risk factor for kidney cancer patients [12]. The genomic structure of the renal cancer patients might play a role in COVID-19 development as the viral infection might be mediated by the activation of virus entrance pathway on the host cell that regulates the expression of several virus invasion genes including ACE2, TMPRSS2, FURIN, CD147/BSG which result in the facilitation of the transmittance of the virus [13-15]. Target gene mutations, which may be triggered kidney carcinogenesis process and could initiate virus entrance changes in the different renal cancer subtypes involving KICH, KIRC, KIRP.

The relationship of target virus entrance genes ACE2, TMPRSS2, FURIN, and CD147/BSG with the pathogenicity of the kidney tumors was examined. We investigated the molecular profiling data of the level of gene expression and mutation analysis in healthy and tumor tissue samples. Thereby, we also explored an epigenetic perspective in the solid tumor. We managed to understand the relationship between the molecular background of multiple receptors and SARS-CoV-2 invasion ways for the pathogenicity of renal cancer subtypes on their susceptibility to COVID-19. New treatment and intervention methods will be developed. In silico analyses were performed to check this hypothesis in the renal cell carcinoma patient compared to healthy tissue samples. The gold standard was wet-lab studies. Therefore, these findings should be confirmed by further experimental studies.

\section{Methods}

\section{Data collection}

The datasets used and/or analyzed during the present study are available from the corresponding author on reasonable request. Raw data is available on the cBioPortal, GEPIA and UALCAN databases.

\section{Genotyping analysis}

The KIRC, KICH and KIRP were chosen as the type of cancers of interest on the web interface to examine mutations in ACE2, TMPRSS2, CD147/ BSG and FURIN genes in KIRC, KICH and KIRP patients presented in the cBio Cancer Genomics Portal (http://cbioportal.org). The selected The Cancer Genome Atlas (TCGA) data set comprised the genome sequencing data of 897 patients. We used algorithm to analyze the mutation distribution of specific protein functional domains using OncoPrint, Cancer Types Summary and Mutation tools by the interface [16]. These tools provide an overview of genomic alterations in particular genes affecting particular individual samples.

\section{Mutation impact analysis}

The possible pathogenicity of the mutations in ACE2, TMPRSS2, CD147/BSG and FURIN genes was evaluated via Polymorphism Phenotyping v2 (PolyPhen-2) (http://genetics.bwh.harvard.edu/pph2), Scanning of unacceptable polymorphisms (SNAP) (https://www. rostlab.org/services/SNAP/), and the Catalog of Somatic Mutations in Cancer (COSMIC) (https://cancer.sanger.ac.uk/cosmic) databases [17-19]. Finally, the evolutionary conservation analyses of the detected mutant amino acids were evaluated among different species via the "Multiple sequence alignment" tool in the PolyPhen-2 software. 


\section{Expression and correlation analysis}

GEPIA is a web server helps that evaluation of the RNA sequencing expression in thousands data of tumors and healthy tissue samples downloading from the TCGA and the genotype-tissue expression (GTEx) projects [20]. The targeted genes (ACE2, TMPRSS2, CD147/BSG and FURIN) expression profiles were shown as box plot graphs obtained from the GEPIA database using $66 \mathrm{KICH}, 523$ KIRC and 286 KIRP patients and healthy tissue samples data downloaded from server. "Boxplots" module of GEPIA allowed us to evaluate the expressions of ACE2, TMPRSS2, CD147/BSG and FURIN genes between tumor and normal tissues. The gene expression levels were analyzed in renal cancer and matched normal tissues based on the GEPIA Platform. The analysis was conducted using the following filters: Expression DIY; Gene, ACE2; datasets selection, KICH, KIRC, KIRP; p-value cut off: 0.05.

The correlation analyses between the expression levels of the ACE2 gene and other targeted genes were also done. The survival analyses of the studied genes according to their gene expression were evaluated using the web interface. The correlation between ACE2 expression and prognosis of overall survival (OS) in renal cancers was also analyzed by GEPIA. The hazard ratio (HR) and P or Cox P values from a log-rank test were included in the plot. $p$-value $\leq 0.05$ was determined statistically significant. "Survival" module of GEPIA allowed us to evaluate the correlation of ACE2, TMPRSS2, CD147/BSG and FURIN expressions with prognosis of renal cancers.

\section{Analysis of promoter methylation levels}

UALCAN is an interactive open-access web source for the analysis of OMICS data (http://ualcan.path.uab.edu/analysis.html). UALCAN provides to use 31 types of cancer RNA-seq and clinical information from TCGA to complete in-depth analyses of TCGA gene expression data, including analysis of the relative expression of a query gene across tumor and normal tissues. The promoter DNA methylation information was from the TCGA Infinium Human Methylation 450K BeadChip arrays. The $t$ test was performed using a PERL script with Comprehensive Perl Archive Network module to compare the statistical significance between two independent groups. This database is built on this network and can be used for approximately 6 , 000 different gene methylation levels [21]. So, the promoter methylation profile of ACE2, TMPRSS2, CD147/BSG and FURIN genes was analyzed with the UALCAN database.

\section{Statistical analysis}

All statistical analyses were performed on the GEPIA database. Kaplan-Meier curves regarding overall survival. Low and high expression groups were compared used the log-rank test. Correlation analyses was performed with Pearson test using online database. The p-value lower than 0.05 is established significant.

\section{Results}

\section{Results of genotyping analysis}

In our study, we selected and analyzed genome sequencing data of a total of $897 \mathrm{KICH}, \mathrm{KIRC}$, and KIRP patients in order to determine the genetic changes in the ACE2, TMPRSS2, CD147/BSG and FURIN genes. We determined that $1.6 \%$ of all KICH, KIRC, and KIRP patients carried at least one genetic mutation (missense, nonsense, deep deletion, and gene amplification) in the related genes. When we look at the frequency of carrying genetic anomalies separately according to cancer types, KIRC was found to be $2.4 \%$, KICH $1.5 \%$ and KIRP $0.8 \%$. In our study, we detected overall seven different mutations (three missense, one nonsense, two frameshift deletions, and one frameshift insertion) for these four genes. The details of these mutations are listed in Table 1. CD147/BSG had genetic mutations in all three cancer types (Figure 1). Studies showed that the coronavirus causing COVID-19 disease was using the ACE2 receptor for the penetration into the host cells like in other coronaviruses like SARS and MERS. ACE2 is a zinc-containing metalloenzyme found on endothelial cells and other cells. A full-length ACE2 enzyme (805 amino acids) constitutes of an N-terminal peptidase domain (PD), single transmembrane helix, and C-terminal collectrin-like domain (CLD), which ends with a 40-residue intracellular segment $[6,7]$. We determined a total of two mutations (one missense, nonsense, and deep deletion) in the ACE2 gene and these mutations were in the KIRC patient group. One of these mutations, p.E489^ nonsense mutation might lead to the formation of a truncated protein as a result of the early termination in the 489th amino acid of the ACE2 polypeptide. The second study gene TMPRSS2 is a type II transmembrane serine protease, which consists of 492 amino acids and is ideally located for the regulation of the cell-to-cell and cell-to-matrix interactions [10]. The linkage of S protein to ACE2 facilitates proteolytic digestion by the host cell proteases like TMPRSS2 and triggers a conformational change in S protein of the coronavirus, which enables the penetration of the viral RNA into the cell leading to the infection of the cell $[3,10,13]$. In our study, we determined one missense mutation (p.L89F) and gene amplification in the TMPRSS2 gene. The detected p.L89f missense mutation was on the cytoplasmic domain. It is believed that the CD147/BSG protein has a key role in the virus-related tumor pathogenesis, cell migration, and the development of chemo-résistance [8]. Studies demonstrated that CD147/BSG was a receptor on the cell and a co-factor facilitating the penetration of the virus. In addition, it is known that CD147/BSG is located on the surface of the human cancer cells and intensively synthesized by the tumor cells and stromal cells in the tumor microenvironment [22]. In our study, we determined one missense mutation p.H169R, 1 frameshift deletion p.L329Wfs 37 in the CD147/BSG gene of KIRP and KICH patients. As a result of this frameshift mutation, the reading frameshifts and dysfunctional proteins may 


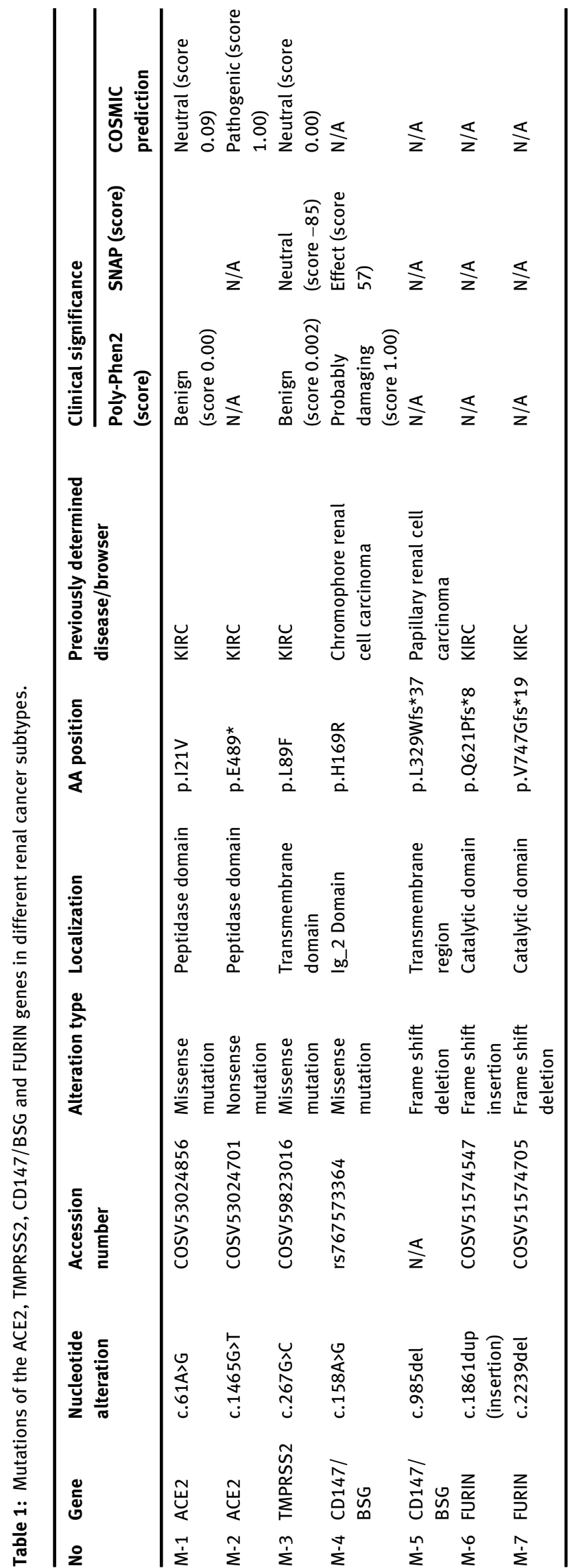

be formed due to the incomplete protein structure. Recently, it was found that SARS-CoV-2 contains four residues (Pro681, Arg682, Arg683, and Ala684) as a potential cutting region for the furin protease of the protein S. Therefore, the FURIN 2 gene, the last gene analyzed in our study, contains two mutations (one frameshift deletion/insertion). Both mutations were detected in the KIRC patient group. We believe that p.Q621Pfs ${ }^{\star} 8$ frameshift insertion may have the properties to change the reading frame, which may lead to the changes in the cutting regions. The location of the determined mutations on the protein domains in the targeted genes is visualized in Figure 2.

\section{Results of impact analysis of detected mutations}

The pathogenic characteristics of the three mutations, which are the missense mutations among the seven mutations that were explained in detail in the mutation analysis chapter according to the analysis done with the Poly-Phen2 database software package and given in Table 1, were determined. As the pathogenic score of the p.H169R missense mutation detected in the Cd147/BSG gene was 1 , we believed that it might have pathogenic (probably damaging) properties. Besides, regarding the analysis done with the SNAP software package, p.H169R was considered as affected as its estimated pathogenicity score was 57 . Using the "multiple sequence alignment" option found in the Poly-Phen2 software, the amino acid sequences, which were affected by the missense mutation points determined between different species during the evolutional process, were compared. According to the results of this analysis, the ACE2 p.I21V and CD147/BSG p.H169R missense mutations were on the evolutionarily conserved amino acids. All estimated pathogenic characteristics and evolutionarily conservation analyses that were performed with the Poly-Phen2 software package were given in detail in Figure 3a-c.

\section{Results of m-RNA expression and correlation analysis}

Gene expression analysis was performed to determine whether the ACE2, TMPRSS2, CD147/BSG and FURIN m-RNA expression profiles belonging to $66 \mathrm{KICH}, 523 \mathrm{KIRC}$ and 286 KIRP cancer patients exhibited differences compared to the healthy subjects. The analysis showed that the ACE2 m-RNA expression level was significantly lower in the KICH patient group and higher in the KIRP 
ACE2

TMPRSS2

BSG

FURIN

$\therefore 0.6 \%{ }^{*}$

Genetic Alteration

$: 0.2 \%$ *

$: 0.5 \%{ }^{*}$

$\therefore \quad 0.3 \%{ }^{*}$

$\square$

|| Missense Mutation (unknown significance) || Truncating Mutation (unknown significance) |Amplification Deep Deletion || No alterations $\quad$ - Not profiled
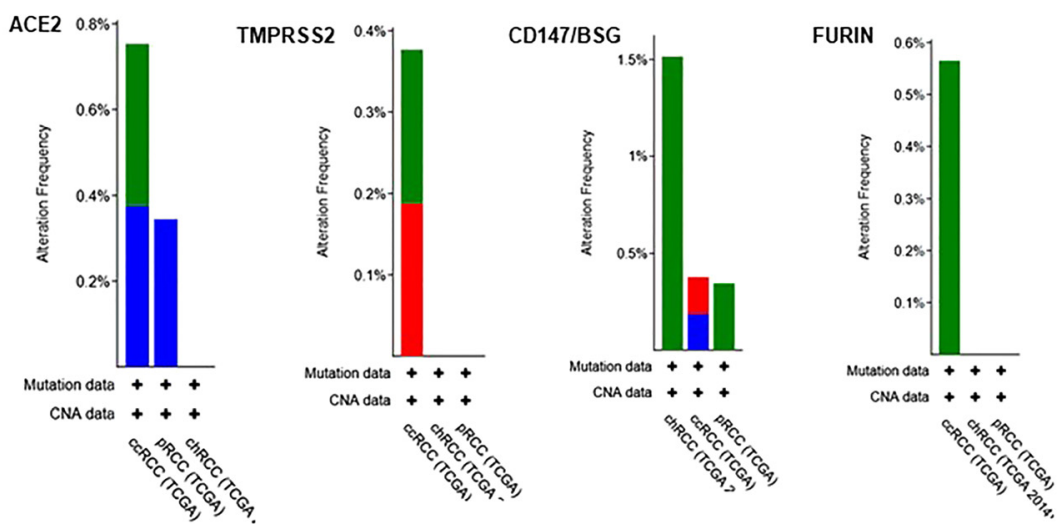

Figure 1: Distribution of genetic alterations in ACE2, TMPRSS2, CD147/BSG and FURIN genes in different renal cancer subtypes (A-D).

patient group compared to the healthy subjects. Although the expression profile in the KIRC group was similar to the KIRP group, the difference was not statistically significant. While the TMPRSS2 m-RNA expression level in the KICH group was higher compared to the KIRC and KIRP groups and healthy subjects, just the opposite was the case in the other two groups and each three expression profiles were statistically significant. The CD147/BSG expression was higher in
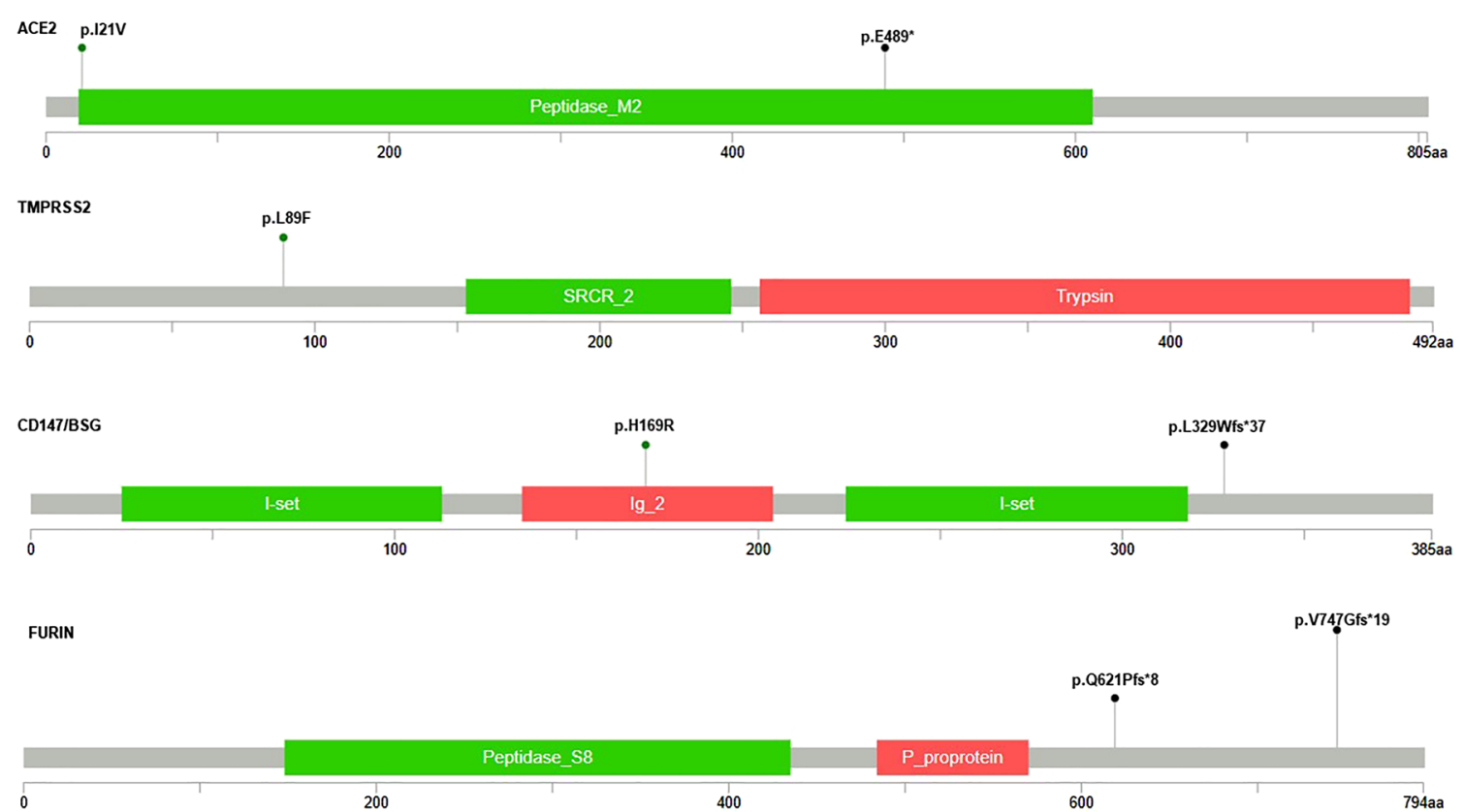

Figure 2: Schematic representation of domain architecture of the ACE2, TMPRSS2, CD147/BSG and FURIN proteins and mutations found in different renal cancer subtypes. (A) Human ACE2 is a polypeptide of 805 amino acids. (B) Human TMPRSS2 is a polypeptide of 492 amino acids (C) Human CD147/BSG is a polypeptide of 385 amino acids. (D) Human FURIN is a polypeptide of 794 amino acids. 
ACE2 p.121V

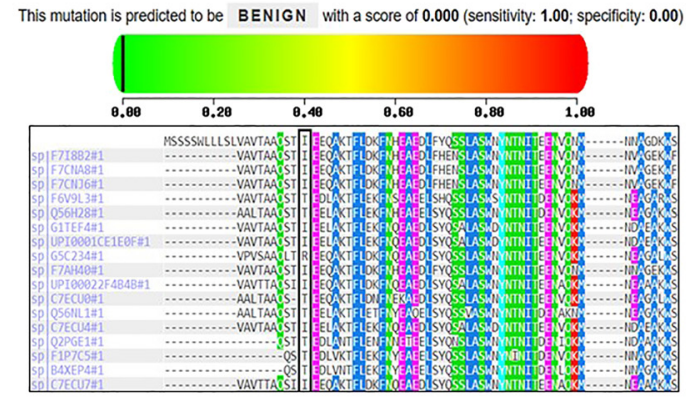

TMPRSS2 p.L89F

C This mutation is predicted to be BENIGN with a score of 0.002 (sensitivity: 0.99 ; specificity: 0.30

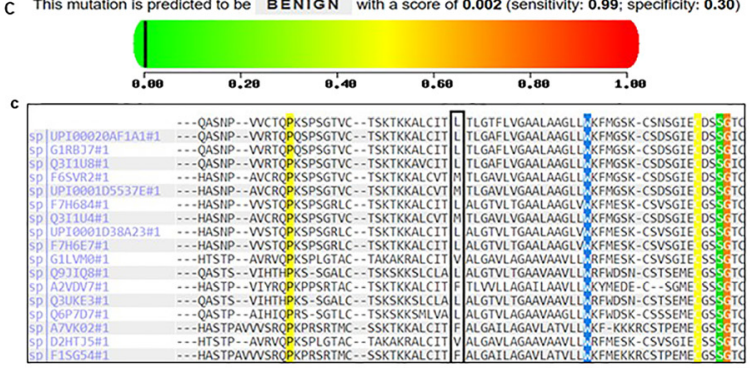

CD147/BSG p.H169R

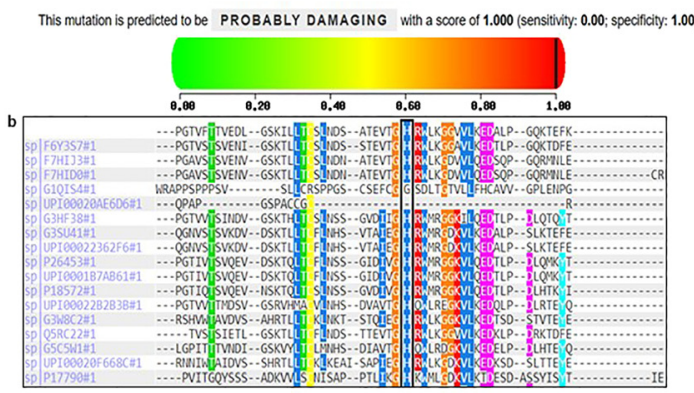


the KICH patient group compared to the other two groups and healthy subjects (Figure 4, p<0.05). There was no statistically significant difference between all three cancer groups for FURIN. Besides, the correlation between the ACE2 m-RNA expression profile and the m-RNA expression profiles of other investigated genes was assessed with the Pearson's correlation test separately and a positive correlation in the KICH group was determined for FURIN (Figure 5, $\mathrm{p}=0.007$ ). Finally, according to the results of survival analysis, KIRP patients with low CD147/BSG expression profiles had a significantly longer general survival time compared to patients with higher expression profiles (Figure 6, $\mathrm{p}=0.009$ ).

\section{Results of promoter methylation levels analysis}

DNA methylation, which has an important function in the suppression of the gene expression, comes into prominence in the development and treatment of cancers, which are considered as the main fatal disease group. Hypomethylation, which is one of the patterns of the DNA methylation, may cause genomic instability and activate related genes. While the ACE2 m-RNA expression profiles had a higher expression level in the cancer subtypes KIRC and KIRP groups compared to the healthy subjects, it was the opposite in the KICH group. According to the results of
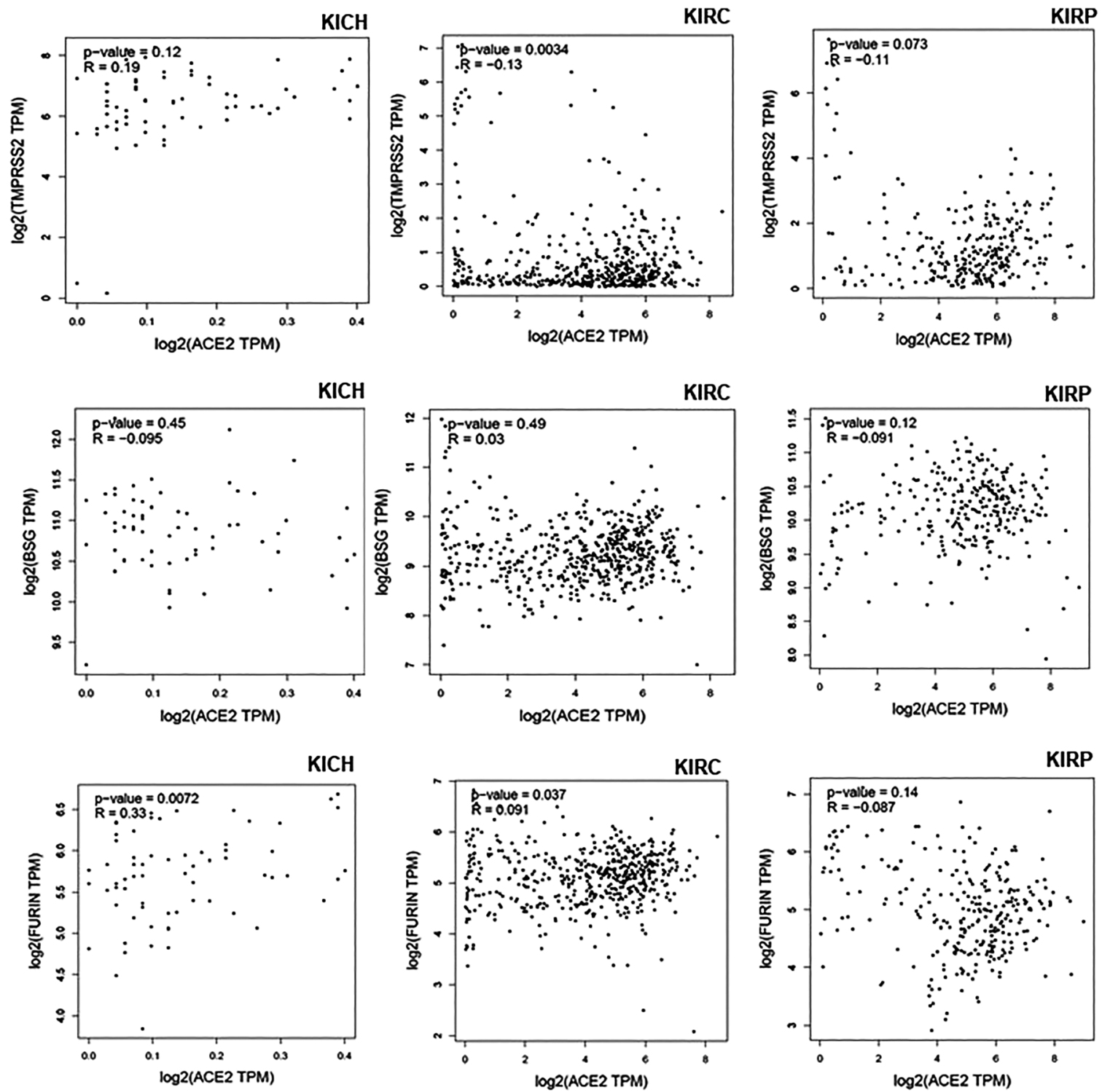

Figure 5: Pearson correlation analyses of TMPRSS2, CD147/BSG and FURIN m-RNA expressions profiles with ACE2 expression in different renal cancer subtypes. 
the analysis performed with the UALCAN database, which is used for the determination of the DNA methylation, the promoter methylation level of ACE2 is significantly lower in the KIRC and KIRP groups compared to the healthy subjects (hypomethylation). On the other hand, regarding the TMPRSS2 and CD147/BSG genes, hyper methylation is observed in the patient groups compared to the healthy subjects. Considering FURIN; KIRC, and KIRP patient groups exhibited hypo methylation and hyper methylation respectively compared to the healthy subjects (Figure 7). Regarding the KICH group, data obtained from the database enabled the analysis between the disease levels.
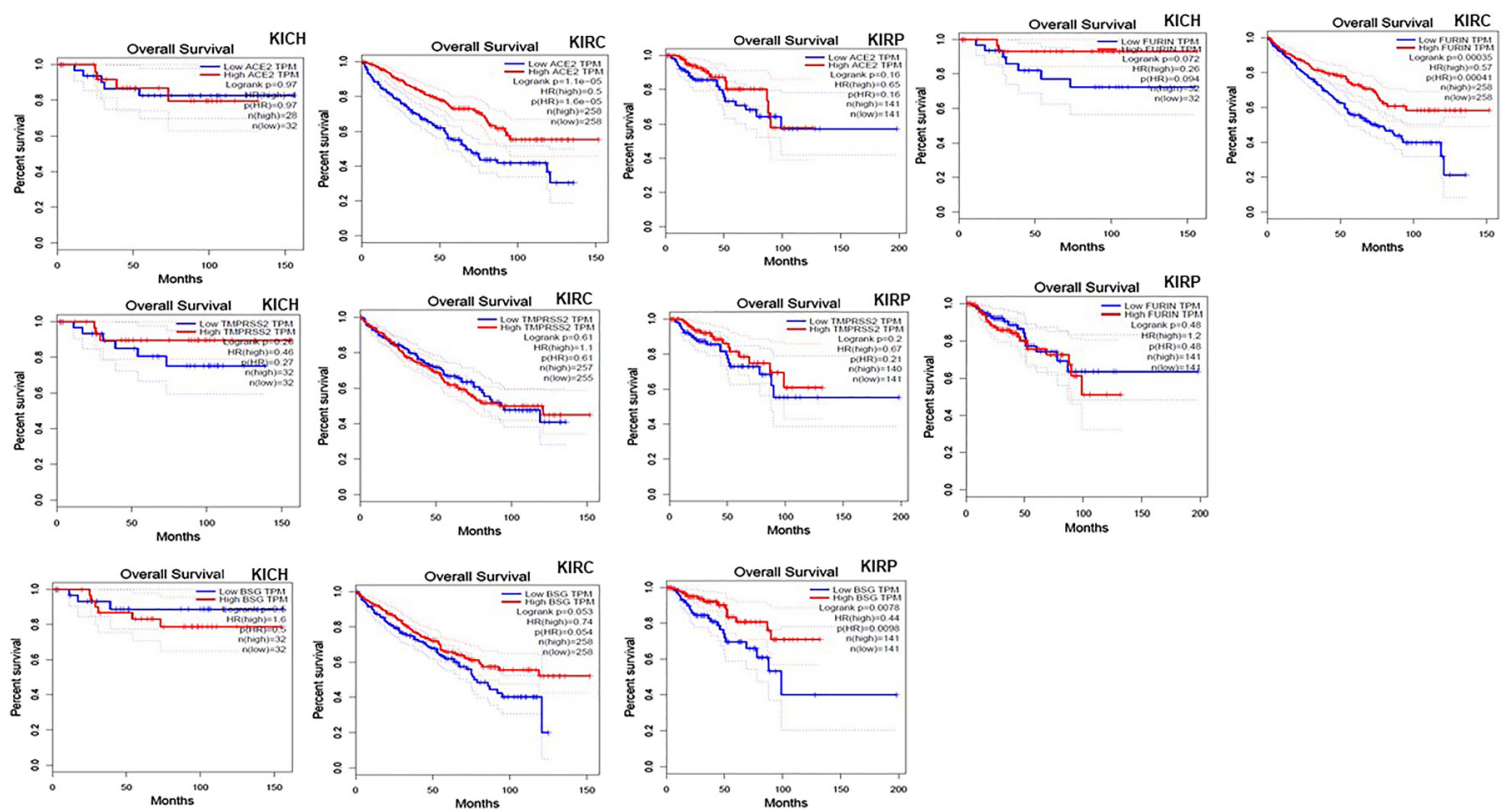

Figure 6: Comparison of Kaplan-Meier survival curves of the high and low expression of ACE2, TMPRSS2, CD147/BSG and FURIN in in different renal cancer subtypes.
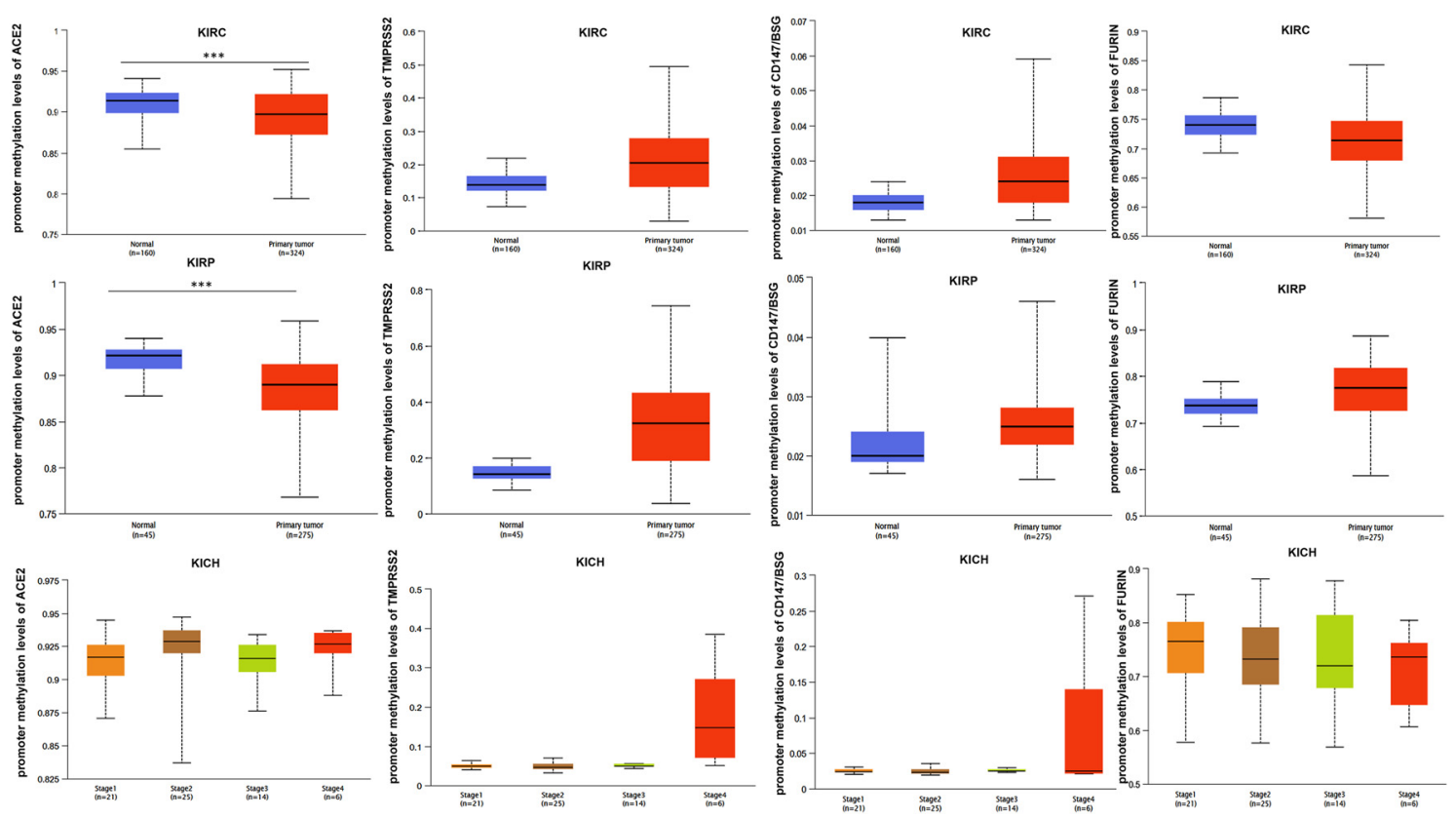

Figure 7: The promoter methylation levels of ACE2, TMPRSS2, CD147/BSG and FURIN in different renal cancer subtypes. 
Particularly, there was statistically significant hyper methylation in stage $4 \mathrm{KICH}$ patient group compared to other groups for TMPRSS2 and CD147/BSG.

\section{Discussion}

Today, the burden of COVID-19 is increasing worldwide and the disease is categorized as a pandemic. In the current study, we presented four virus entrance genes with biological mechanisms with in silico analysis demonstrating their important roles in the relationship between COVID-19 and cancer and highlight the role of these genetic and epigenetic mechanisms in distinct invasion pathways of the SARS-CoV-2.

The first area is based on genetic, where the interactions of SARS-CoV-2-tumor cells have been reported in human lung cancer [23, 24]. The invasion of the RNA virus involves the help of the target in the human host. In the human host, infection occurs through the binding of the ACE2 receptor that transmits virus into the human host cells $[3,13,15,25]$. Recent studies demonstrated that other genes including CD147/BSG, TMPRSS2 and FURIN have an important role in the transmission of the virus [7-10,24-26]. So, we explained the mutation, mRNA expression, methylation profiles of ACE2; TMPRSS2, CD147/BSG and FURIN genes in the KICH, KIRC and KIRP sample groups, which are known to be the subtypes of renal cancer. Distinct molecular patterns are associated with ACE2 expression in RCC. This study attempted to provide more information on the role of four important genes associated with SARS-CoV-2 in renal cancer subtypes. A comprehensive analysis of the literature showed that genomic and functional properties of ACE2, TMPRSS2, CD147/BSG and FURIN genes for potential sensitivity and/or resistance in SARS-CoV-2 infection in renal cancer were effective. We think that the frameshift mutations, especially in the CD147/BSG and FURIN genes, will change the reading frame and result in a functionally inadequate peptide. The p.H169R mutation in the CD147/BSG gene is between the codon 22 and codon 205, amino acids encode the gene's extracellular domain and may disrupt the protein's extracellular functional properties. We determined p.I21V missense mutations in the CD147/BSG gene. Therefore, mutations that may occur in these amino acids may be capable of disrupting the function, structural and conformational properties of the protein. We also detected that deep deletions which are probably homozygous in the ACE2 and CD147/BSG genes might affect the expression of the gene Gene amplifications, which are also observed in the TMPRSS2 and CD147/BSG gene, are capable of causing uncontrolled and excessive gene expression. The p.E489* nonsense mutation in the ACE2 gene truncates mutation and we think that 805 amino acid long ACE2 protein synthesis will cause deficient or immature enzyme with the formation of a stopped codon, which may lead to a disruption in protein function. The analysis of ACE2, TMPRSS2, CD147/BSG and FURIN genes in the KICH, KIRC and KIRP patient groups showed that the KIRC and KIRP had a significantly higher rate of expression for the ACE2 gene compared to the healthy group and the KICH group in the present study. Low ACE2 expression in the KICH patient group may be protective against the SARS-CoV-2 infection. The SARS-CoV-2 causes spike protein to directly bind with the host cell surface ACE2 receptor or CD147/BSG membrane protein and facilitate the entrance and replication of the virus. Thus, differences of genes that play roles in all renal cell carcinomas could have significance in the biology and entrance power of SARS-CoV2. Thereby, associations between COVID-19 and cancer are possible and previous studies indicate that the expression of ACE2 is related to lung cancer [23, 25, 27]. Moreover, we found that ACE2 was highly expressed in the KIRC and KIRP. We predict that cancer patients of KIRC and KIRP might also have a major entry region for SARS-CoV-2 and that the infection of this patient group might have increased susceptibility.

Another area is based on the epigenetic, transcriptional and promoter methylation alterations includes the virus entrance pathways as examined across all RCC subtypes and a comprehensive view of the virus entrance pathway in RCC subtypes. Yang et al. reported that ACE2 promoter methylation levels were significantly reduced in KIRP subtype of renal cancer. The same study emphasized that increased ACE2 expression was also related to the immune infiltration and tumor tissue caused susceptibility to SARS-CoV-2 and poor prognosis [28]. We reported that there was significant hypermethylation in stage four of the KICH cancer group compared to other groups for TMPRSS2 and CD147/BSG genes and the promoter methylation levels of ACE2 in KIRC and KIRP were significantly reduced. Furthermore, while this ACE2 gene variant evolved the confer susceptible against SARS-CoV-2 infection, recent evidence suggests that CD147/BSG and serine proteases TMPRSS2, FURIN also influences the entrance of the virus to host mammalian cells $[3,6-10,29,30]$.

Consequently, these genes selected for SARS-CoV-2 could also impact cancer outcomes in kidney subgroups. The KIRP patients with a low CD147/BSG expression profile had significantly longer overall survival times than those with a higher expression of these genes. We concluded that 
kidney cancer patients may be more sensitive to SARS-CoV2 infection, which may worsen the prognosis.

Acknowledgments: The data used in our study are obtained from public database the TCGA Research Network: https:// www.cancer.gov/tcga. We thank the TCGA and GEPIA databases for the availability of the data.

Research funding: None declared.

Author contributions: All authors have accepted responsibility for the entire content of this manuscript and approved its submission. Concept - D.FA.B., R.I.S.; Design - D.FA.B., R.I.S.; Supervision - D.FA.B., R.I.S.; Funding - None; Materials D.FA.B., R.I.S.; Data collection and/or processing - D.FA.B.; Data analysis and/or interpretation - D.FA.B., R.I.S.; Literature search - D.FA.B., R.I.S.; Writing - D.FA.B., R.I.S.; Critical review - R.I.S.

Competing interest: There are no conflicts of interest among the authors.

Ethical approval and ethical standards: The data used in our study were obtained from public database TCGA, therefore, ethical approval was not required.

Availability of data and materials: The datasets generated and analyzed during the current study are available in TGCA database (https://www.cancer.gov/tcga), The cBio cancer genomics portal (http://www.cbioportal.org/).

\section{References}

1. Li H, Liu SM, Yu XH, Tang SL, Tang CK. Coronavirus disease 2019 (COVID-19): current status and future perspectives. Int J Antimicrob Agents 2020;29:105951.

2. Chen Y, Liu Q, Guo D. Emerging coronaviruses: genome structure, replication, and pathogenesis. J Med Virol 2020;92:418-23.

3. Lan J, Ge J, Yu J, Shan S, Zhou H, Fan S, et al. Structure of the SARS-CoV-2 spike receptor-binding domain bound to the ACE2 receptor. Nature 2020;581:215-20.

4. Hickling DR, Sun $\Pi$, Wu XR. Anatomy and physiology of the urinary tract: relation to host defense and microbial infection. Microbiol Spectr 2015;3:2012-16.

5. Moujaess E, Kourie HR, Ghosn M. Cancer patients and research during COVID-19 pandemic: a systematic review of current evidence. Crit Rev Oncol Hematol 2020;150:102972.

6. Dai YJ, Hu F, Li H, Huang HY, Wang DW, Liang Y. A profiling analysis on the receptor ACE2 expression reveals the potential risk of different type of cancers vulnerable to SARS-CoV-2 infection. Ann Transl Med 2020;8:481.

7. Zhang H, Penninger JM, Li Y, Zhong N, Slutsky AS. Angiotensinconverting enzyme 2 (ACE2) as a SARS-CoV-2 receptor: molecular mechanisms and potential therapeutic target. Intensive Care Med 2020;46:586-90.

8. Ulrich H, Pillat MM. CD147 as a target for COVID-19 treatment: suggested effects of azithromycin and stem cell engagement. Stem Cell Rev Rep 2020;16:434-40.
9. Gordon DE, Jang GM, Bouhaddou M. A SARS-CoV-2 protein interaction map reveals targets for drug repurposing. Nature 2020;583:459-68.

10. Hoffmann M, Kleine-Weber H, Schroeder S, Krüger N, Herrler T, Erichsen S, et al. SARS-CoV-2 cell entry depends on ACE2 and TMPRSS 2 and is blocked by a clinically proven protease inhibitor. Cell 2020;181:271-80.e8.

11. Muglia VF, Prando A. Renal cell carcinoma: histological classification and correlation with imaging findings. Radiol Bras 2015;48:166-74.

12. Zhou F, Yu T, Du R, Fan G, Liu Y, Liu Z, et al. Clinical course and risk factors for mortality of adult inpatients with COVID-19 in Wuhan, China: a retrospective cohort study. Lancet 2020;395: 1054-62.

13. Hussain M, Jabeen N, Raza F, Shabbir S, Baig AA, Amanullah A, et al. Structural variations in human ACE2 may influence its binding with SARS-CoV-2spike protein. J Med Virol 2020;92: 1580-6.

14. Walls AC, Park YJ, Tortorici MA, Wall A, McGuire AT, Veesler D. Structure, function, and antigenicity of the SARS-CoV-2 spike glycoprotein. Cell 2020;181:281-92.e6.

15. Gheblawi M, Wang K, Viveiros A, Nguyen Q, Zhong JC, Turner AJ, et al. Angiotensin converting enzyme 2: SARS-CoV-2 receptor and regulator of the renin-angiotensin system. Circ Res 2020;126: 1456-74.

16. Cerami E, Gao J, Dogrusoz U, Gross BE, Sumer SO, Aksoy BA, et al. The cBio cancer genomics portal: an open platform for exploring multidimensional cancer genomics data. Canc Discov 2012;2: 401-4.

17. Adzhubei I, Jordan DM, Sunyaev SR. Predicting functional effect of human missense mutations using PolyPhen-2. Curr Protoc Hum Genet 2013:7.20.1-41. Chapter7:Unit7.20.

18. Bromberg Y, Rost B. SNAP: predict effect of non-synonymous polymorphisms on function. Nucleic Acids Res 2007;35:3823-35.

19. Tate JG, Bamford S, Jubb HC, Sondka Z, Beare DM, Bindal N, et al. COSMIC: the catalogue of somatic mutations in cancer. Nucleic Acids Res 2019;47:D941-7.

20. Tang Z, Li C, Kang B, Gao G, Li C, Zhang Z. GEPIA: a web server for cancer and normal gene expression profiling and interactive analyses. Nucl Acids Res 2017;45:W98-102.

21. Chandrashekar DS, Bashel B, Balasubramanya SAH, Creighton CJ, Ponce-Rodriguez I, Chakravarthi BVSK, et al. UALCAN: a portal for facilitating tumor subgroup gene expression and survival analyses. Neoplasia 2017;19:649-58.

22. Landras A, Reger de Moura C, Jouenne F, Lebbe C, Menashi S, Mourah S. CD147 is a promising target of tumor progression and a prognostic biomarker. Cancers (Basel) 2019;6:11.

23. Lukassen S, Chua RL, Trefzer T, Kahn NC, Schneider MA, Muley T, et al. SARS-CoV-2 receptor ACE2 and TMPRSS2 are primarily expressed in bronchial transient secretory cells. EMBO J 2020;4: e105114.

24. Kong Q, Xiang Z, Wu Y, Gu Y, Guo J, Geng F. Analysis of the susceptibility of lung cancer patients to SARS-CoV-2 infection. Mol Canc 2020;19:80.

25. Guzzi PH, Mercatelli D, Ceraolo C, Giorgi FM. Master regulator analysis of the SARS-CoV-2/human interactome. J Clin Med 2020; 9. https://doi.org/10.3390/jcm9040982.

26. Coutard B, Valle C, de Lamballerie X, Canard B, Seidah NG, Decroly E. The spike glycoprotein of the new coronavirus 2019-nCoV 
contains a furin-like cleavage site absent in CoV of the same clade. Antivir Res 2020;176:104742.

27. Li G, He X, Zhang L, Ran Q, Wang J, Xiong A, et al. Assessing ACE2 expression patterns in lung tissues in the pathogenesis of COVID-19. J Autoimmun 2020;13:102463.

28. Yang J, Li H, Hu S, Zhou Y. ACE2 correlated with immune infiltration serves as a prognostic biomarker in endometrial carcinoma and renal papillary cell carcinoma: implication for COVID-19. Aging (Albany NY) 2020;12:6518-35.

29. Li MY, Li L, Zhang Y, Wang XS. Expression of the SARS-CoV-2 cell receptor gene ACE2 in a wide variety of human tissues. Infect Dis Poverty 2020;9:45.

30. Soleimani M. Acute kidney injury in SARS-CoV-2 infection: direct effect of virus on kidney proximal tubule cells. Int J Mol Sci 2020;5:21. 